\title{
An operationally relevant framework for mapping spot fire transmission potential ${ }^{+}$
}

\author{
Benjamin M. Gannon ${ }^{1, *}$, Matthew P. Thompson ${ }^{2}$ and Yu Wei ${ }^{1}$ \\ 1 Department of Forest and Rangeland Stewardship, Colorado State University, Fort Collins, CO 80523, \\ USA; benjamin.gannon@colostate.edu (B.M.G.); yu.wei@colostate.edu (Y.W.) \\ 2 Rocky Mountain Research Station, USDA Forest Service, Fort Collins, CO 80526, USA; \\ matthew.p.thompson@usda.gov \\ * Correspondence: benjamin.gannon@colostate.edu \\ † Presented at the 1st International Electronic Conference on Forests, 15-30 November 2029; Available \\ online: https://iecf2020.sciforum.net/
}

Published: 14 November 2020

\begin{abstract}
Spotting is an important fire spread mechanism and cause of fireline breaches, yet current models provide only coarse metrics of spotting behavior that are underutilized in fire operations. We developed a spatial framework to quantify and map potential sources and sinks of spot fire transmission across control lines based on models of ember production, ember transport, and receiving fuel bed ignition probability. The framework provides several spatially explicit measures of spotting potential (SP) conditional on fire extent and weather that are designed to inform control line selection and resource allocation to tasks such as line prep, retardant application, and holding operations. We evaluated the utility of SP using two wildfire case studies with growth episodes attributed to spotting. SP captured the general trends in spotting behavior from these wind-driven fires. In its current form, SP may be useful for relative evaluation of control lines, and to help managers think prescriptively about the control tactics necessary on both the source and receiving sides of control lines to avoid spotting breaches. Future research priorities are refining the component models and empirical calibration of SP to spotting probability.
\end{abstract}

Keywords: spotting; embers; wildfire transmission; wildfire containment; fireline evaluation

\section{Introduction}

Spotting complicates fire containment and threatens the safety of suppression personnel and the public. Fire containment models that focus on interrupting surface fire spread with fireline construction have limited utility for suppression planning because they do not consider spotting or related suppression tasks. Spotting decreases containment probability, but the magnitude of this effect and the factors that influence it have not been systematically quantified in many environments [1-5]. Spotting processes are represented in simulation models used to predict fire spread, arrival times, and burn probability [6-8], but there are no equivalent models to quantify conditional metrics of spot fire transmission potential across control lines. We also lack tools to inform resource allocation to suppression tasks aimed at reducing spotting such as vegetation clearing, suppression firing, or mop up to decrease ember production; prophylactic application of fire retardant to reduce fire intensity and ignition probability; and holding operations to contain spot fires.

Fire containment models have either assumed all constructed fireline will hold (e.g., [9]) or that containment probability increases with control line width and decreases with fire intensity [10]. The latter is attractive because of its ability to estimate the resource needs to construct fireline with a desired level of reliability [11]. Wilson's [2] firebreak experiments validate that this framework is appropriate for surface fire but also show that containment probability decreases in the presence of 
spotting prone vegetation. The risk of spotting is mitigated during fire operations with variety of tactics including fuels reduction, retardant and water application, burnout, mop-up, holding with hand or engine crews, and spot fire patrol and containment with ground or aerial resources. Albini's [6] vision that his model would be used to inform these actions has yet to be fully realized. Describing the magnitude and spatial distribution of SP is a logical starting point to inform fire management decisions; for example, fireline segments with high transmission potential could be avoided in planning or targeted for mitigation, ember source mapping could inform the depth of necessary fuels reduction, and areas with high receiving potential could be prioritized for patrol.

Beyond the empirical model of Wilson [2], we have limited understanding of how spotting influences containment probability. Landscape-scale evaluation of control potential based on statistical associations of historical fire perimeters with environmental factors is gaining popularity $[12,13]$ but spread mechanisms have not been explicitly addressed in this research. Spotting is modeled in fire simulation systems used to inform incident management, such as FARSITE [7] and FSPro [8], but their stochastic representation of spotting and reliance on users to set key model parameters make them inefficient and potentially inconsistent tools to characterize SP. Related prefire transmission risk analyses account for spotting in similar ways [14,15]. Burn probability products from these analyses do not directly communicate spread mechanisms, nor do they easily inform resource needs for suppression tasks that would benefit from spatially explicit predictions of spotting sources and sinks. However, the underlying conceptual model of spotting in these systems $[6,16]$ provides a sound basis for mapping ember source areas, transport paths, and landing locations that could be applied to containment-focused SP assessment.

The goal of this paper is to introduce an operationally relevant spatial framework to characterize spot fire transmission potential conditional on specified fire extent and weather. We first describe how models of ember production, transport, and ignition probability are combined to quantify SP for source, receiving, and transmitting units of the landscape. We then apply the framework to two wind-driven wildfires in Colorado, USA to demonstrate its utility for evaluating SP across control lines and suppression resource needs.

\section{Materials and Methods}

\subsection{Spotting Potential Framework}

The intent of the SP framework is to combine models of ember production, transport, and receiving fuelbed ignition to produce a conditional measure of spot fire transmission potential for a given fire extent and weather scenario. We demonstrate the framework with data sources and models commonly used by fire managers in forested areas of the USA.

Like others, we assume spotting only occurs when canopy fuels are engaged in combustion $[6,16]$. Instead of randomly generating ember quantities based on user supplied spotting probabilities [16], we assume ember production is proportional to the mass of canopy fuels engaged in combustion, which we estimate as the product of canopy bulk density (CBD), a measure of canopy fuel mass per unit volume $\left(\mathrm{kg} \mathrm{m}^{-3}\right)$, and crown fraction burned (CFB), a prediction of canopy proportion engaged in combustion. CBD is quantified with spatial data from LANDFIRE [17]. CFB is modeled for each raster cell with FlamMap [16] using the Scott and Reinhardt [18] method for crown fire activity. Relative ember production (EP) is then calculated as the product of CBD and CFB linearly re-scaled so that $0.25 \mathrm{~kg} \mathrm{~m}^{-3}$, the approximate mean of $\mathrm{CBD}$ for common forest types in western North America [19], corresponds to the maximum value of 100 (Equation (1)).

$$
\text { If } \mathrm{CBD} \times \mathrm{CFB} \leq 0.25 \mathrm{~kg} \mathrm{~m}^{-3}, \mathrm{EP}=400 \times \mathrm{CBD} \times \mathrm{CFB} \text {; else, } \mathrm{EP}=100 \text {, }
$$

Ember transport is modeled with the FlamMap [16] implementation of Albini [6], which predicts maximum spotting distance (MSdist) and direction (MSdir) for each source pixel as a function of ember lofting height, horizontal transport by surface winds, and burn time. Lofting height is influenced by the number of torching trees, which is estimated from canopy cover and CFB [16]. Physical modeling studies of spotting suggest that ember landing density should peak near the 
source and decline with increasing distance [20-23]. We approximate this trend using a lognormal distribution with the mode (Mo) set to one quarter of MSdist (Equation (2)) and the mean of the distribution $(\mu)$ calculated assuming a standard deviation $(\sigma)$ of 0.5 (Equation (3)). This parameterization ensures the probability of exceeding MSdist is less than or equal to 0.01 . Future work will focus on refining these parameters.

$$
\begin{gathered}
\mathrm{Mo}=0.25 \times \text { MSdist }, \\
\mu=\log (\mathrm{Mo})+\sigma^{2},
\end{gathered}
$$

A series of ember landing points are then generated at fixed intervals ( $30 \mathrm{~m}$ in this study) along a transect from the source pixel to the maximum transport point. Each point is attributed with a probability density $(f(x))$ of reaching the specified transport distance using Equation 4 and the probability densities are rescaled so that they sum to one for the transect.

$$
f(x)=1 /(x \sigma \times \operatorname{sqrt}(2 \pi)) \times \exp \left(-(\ln (x)-\mu)^{2} / 2 \sigma^{2}\right),
$$

Ignition probability (IP) is quantified for each ember landing location based on Andrews adaptation of Schroeder [24], which incorporates ambient temperature, fine fuel moisture (1-hr fuels), and percent shading [25]. Percent shading is approximated using percent canopy cover from LANDFIRE [17]. Ambient temperature and fine fuel moisture are set by the user. Zero IP is assigned to embers that land in non-burnable fuel types.

SP is a unitless index calculated for a single source pixel and ember landing location as the product of EP, transport distance $f(x)$, and IP (Equation (5)). SP can also be summed for an area or barrier of interest (Equation (6)).

$$
\begin{gathered}
\mathrm{SP}=\mathrm{EP} \times f(x) \times \mathrm{IP}, \\
\mathrm{SP}=\operatorname{SUM}\left(\mathrm{EP}_{\mathrm{i}} \times f(x)_{\mathrm{i}} \times \mathrm{IP}_{\mathrm{i}}\right) \mid \mathrm{i}=1 \text { to } \mathrm{i}=\mathrm{N},
\end{gathered}
$$

The spatial topology of SP (Figure (1)) can inform fire management tasks focused on source, receiving, and transmitting units of the landscape. We define: source SP (SSP) as the total SP produced from a user-defined spatial unit (a raster cell or a multi-cell polygon) on the fire side of a control line, receiving SP (RSP) as the sum of SP delivered to a spatial unit on the green side of a control line, and transmitted SP (TSP) as the sum of SP that is transported across a control line from source to receiving unit(s).
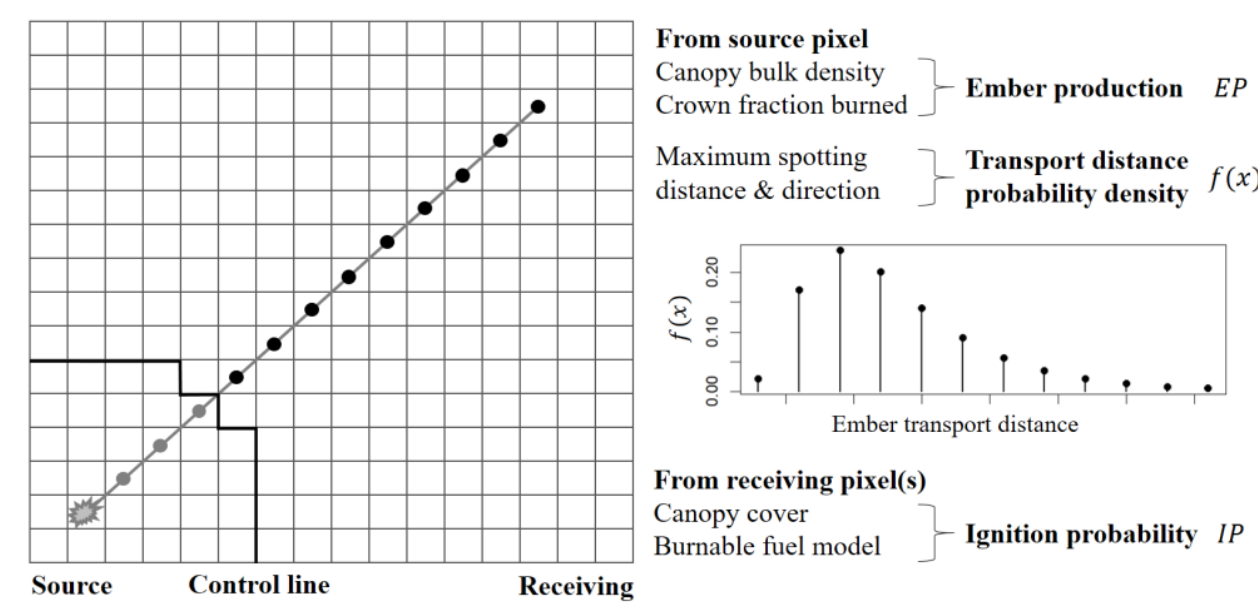

Figure 2. The spatial topology of the spotting potential (SP) framework is shown for a single source pixel on the fire side of the control line and the transect between the source pixel and maximum transport point. Only embers that land on the receiving side of the control line contribute to (SP). 
We developed our prototype SP model in R version 3.5 .3 [26] using the following packages: raster version 2.8-19, rgdal version 1.4-3, rgeos version 0.4-2, and plyr version 1.8.4 [27-30]. We utilized a command line version of FlamMap (Missoula Fire Sciences Laboratory, Missoula, MT) to calculate the basic fire behavior inputs including CFB, MSdist, and MSdir.

\subsection{Test Cases}

We applied the SP framework to two wildfire incidents in Colorado, USA (Figure (2)) to evaluate its utility for containment planning.
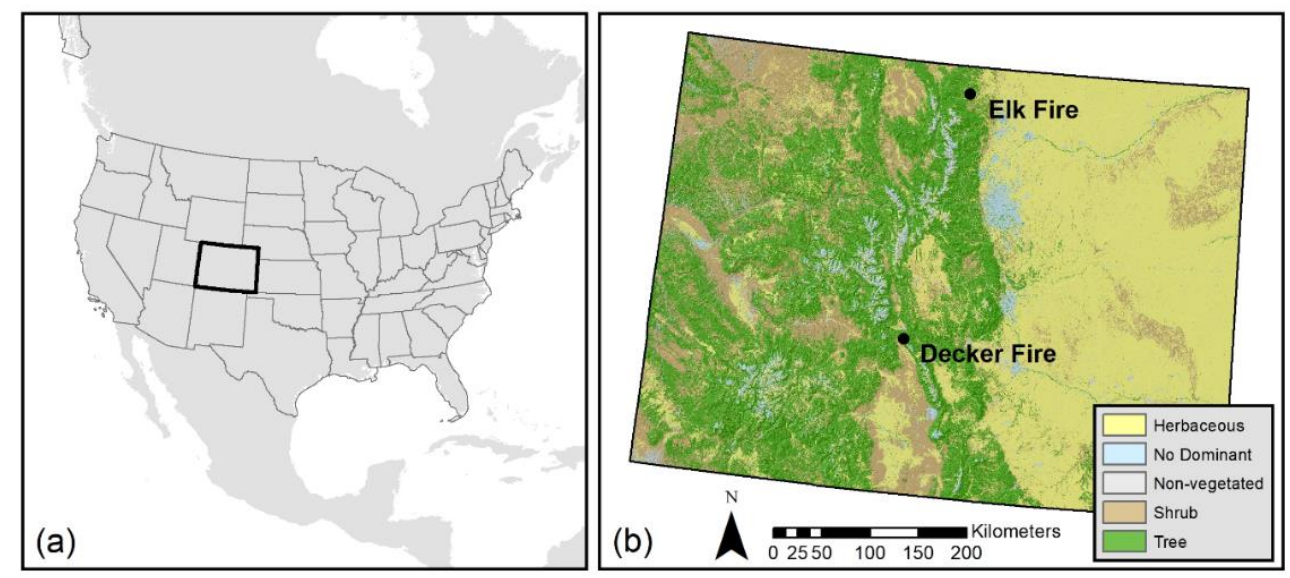

Figure 2. (a) Location of Colorado in North America. (b) Location of the test case fires in Colorado relative to major vegetation types from LANDFIRE [17].

The first test case is the 2019 Decker Fire that started on September 8, 2019 approximately $12 \mathrm{~km}$ south of Salida, Colorado. We use this case to evaluate how well RSP aligns with observed spotting behavior. We reconstructed spotting activity during the September 30th burn period using perimeter data derived from aerial infrared imagery [31] like Storey et al. [5]. New areas of fire growth on September 30th that did not intersect the previous daily perimeter were classified as spot fires. This excludes any spot fires that merged with the main fire during the burn period. Environmental conditions were approximated using the fuel moisture conditions at time 13:00 from the closest weather station (Bear Creek 053905) and the highest gust speeds documented in the incident report [32] (Table (1)). We assumed the containment objective was to limit fire spread to the main fire extent at the end of the burn period.

The second case study is the 2019 Elk Fire that started on October 16, 2019 near Red Feather Lakes, Colorado as the Elkhorn Prescribed Fire. The prescribed fire spotted across the containment lines due to strong winds. An after-action review documents the approximate locations of the spot fires, suspected ember source areas, and observed weather [33]. We use this case to evaluate whether SP aligns with observed spotting behavior on the day of the escape. Environmental conditions for this run were set to the minimum hourly fuel moistures near the time of the escape and the approximate maximum gust speed and direction from on-site observations and the nearest weather station (Red Feather 050505) (Table (1)). We then model SP for the planned prescribed fire extent and weather scenarios from the burn plan [33] to illustrate how spotting magnitudes, evaluation of spotting risk, and tactics could adapt to changing weather. In both cases, we assumed the containment objective was to limit fire to the planned prescribed fire extent. 
Table 1. Fire environment characteristics for the test cases. Terrain influences on wind were modeled at $90 \mathrm{~m}$ resolution in FlamMap.

\begin{tabular}{|c|c|c|c|c|c|c|c|c|c|}
\hline Fire scenario & $\begin{array}{l}\text { Fire } \\
\text { Size } \\
\text { (ha) }\end{array}$ & $\begin{array}{c}\text { Wind } \\
\text { speed } \\
(\mathrm{kph} @ 6 \\
\mathrm{m})\end{array}$ & $\begin{array}{l}\text { Wind } \\
\text { dir. } \\
\text { (deg) }\end{array}$ & $\begin{array}{c}\text { Temp } \\
\text { (deg } \\
\text { C) }\end{array}$ & $\begin{array}{l}\text { 1-hr } \\
\text { F.M. } \\
(\%)\end{array}$ & $\begin{array}{c}\text { 10-hr } \\
\text { F.M. } \\
(\%)\end{array}$ & $\begin{array}{c}\text { 100-hr } \\
\text { F.M. } \\
\text { (\%) }\end{array}$ & $\begin{array}{c}\text { Herb. } \\
\text { F.M. } \\
(\%)\end{array}$ & $\begin{array}{c}\text { Woody } \\
\text { F.M. } \\
(\%)\end{array}$ \\
\hline Decker & 885 & 72.4 & 180 & 18.3 & 2 & 4 & 8 & 30 & 65 \\
\hline Elk - observed & 50 & 64.4 & 248 & 21.1 & 2 & 3 & 7 & 30 & 60 \\
\hline Elk - low & 200 & 16.1 & 225 & 4.4 & 13 & 15 & 17 & 60 & 90 \\
\hline Elk - preferred & 200 & 29.0 & 225 & 21.1 & 7 & 9 & 12 & 40 & 70 \\
\hline Elk - high & 200 & 38.6 & 225 & 29.4 & 4 & 6 & 8 & 30 & 60 \\
\hline
\end{tabular}

\section{Results}

\subsection{Decker Fire}

RSP captured the general trends in spot fire occurrence during the September 30th burn period (Figure (3)). Of the 62 spot fires observed during the burn period, $43(69.4 \%)$ were within $30 \mathrm{~m}$ of mapped RSP. Many of the remaining 19 spot fires would align with RSP modeled for slightly higher wind speeds or slight variations in wind direction but spotting activity in the northwest and southeast quadrants did not align well with RSP. Spot fires occasionally exceeded the modeled transport distances, but many of the spot fires were close to the main fire. Figure (4) compares RSP within $30 \mathrm{~m}$ of observed spot fires against RSP without nearby spot fires. The RSP distribution near spot fires is skewed towards higher values, but some spot fires were observed in areas with low RSP.

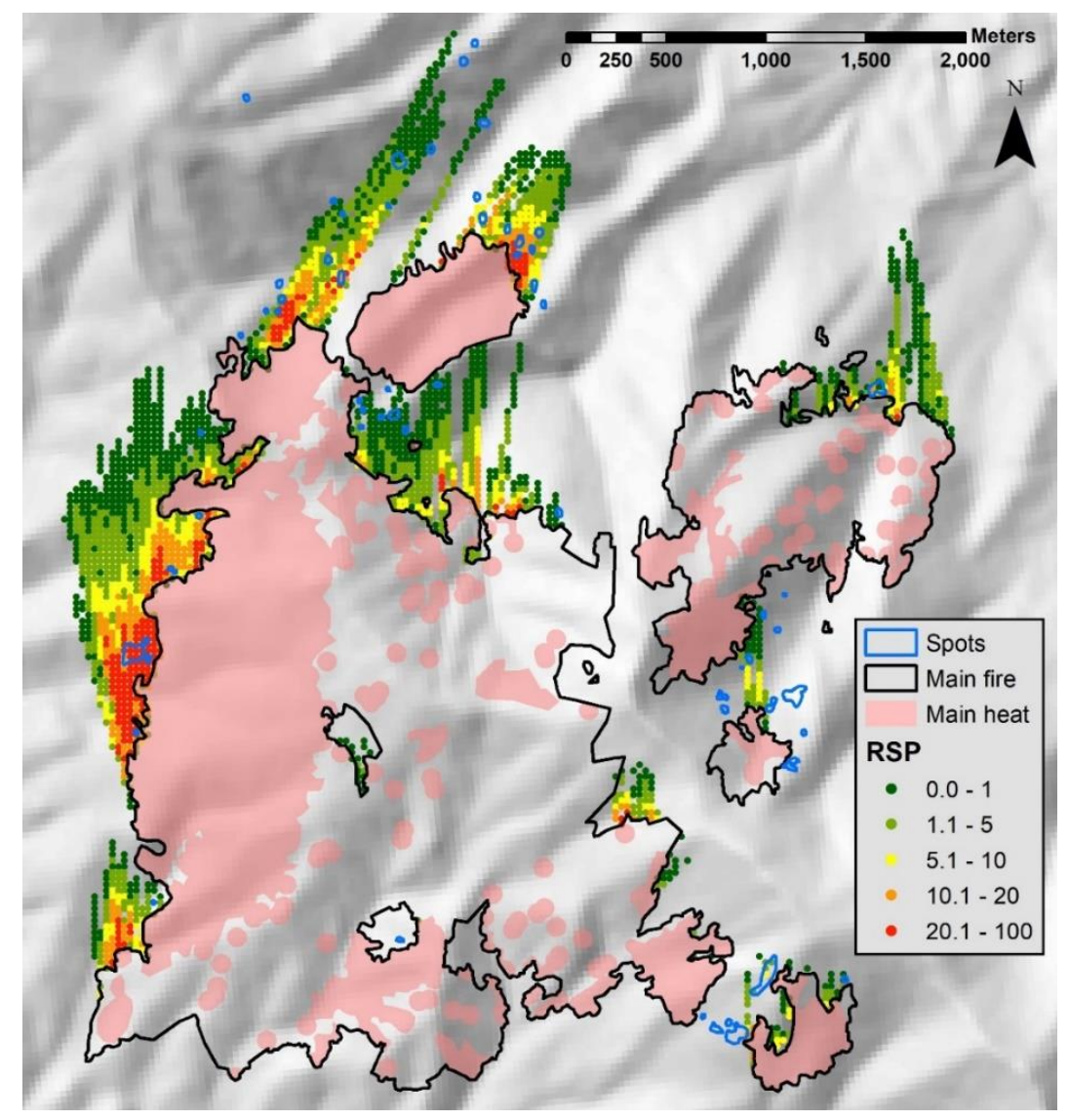

Figure 3. Receiving spotting potential (RSP) for the September 30, 2019 burn period. The main fire is defined as any area that intersects the previous daily perimeter. Spots fires reflect new growth that is 
discontinuous with the previous daily perimeter. Areas with intense, scattered, or isolated heat within the main fire were considered potential ember sources.
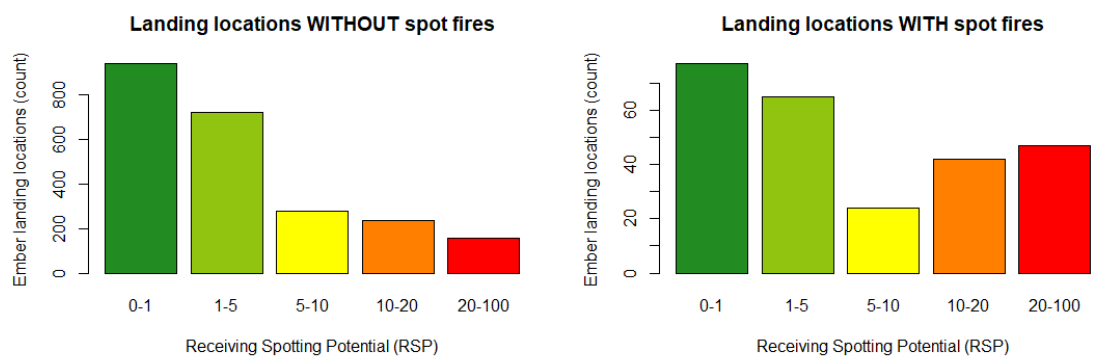

Figure 4. Receiving spotting potential (RSP) distributions for the September 30, 2019 burn period for ember landing locations without spot fires and with spot fires.

\subsection{Elk Fire}

SSP and RSP modeled for the observed weather conditions are shown in Figure (5). Under these weather conditions, much of the unit has potential to produce embers that could cross the containment lines. The suspected ember source locations are in areas with high SSP. Counter to our ember production sub-model, large downed fuels may have been the source of the escaped embers, but it is also possible that the embers were generated from the observed single tree torching in the same or nearby areas [33]. These hillslopes were actively burning during the escape and their higher position than the planned containment line in valley bottom reduces the lofting height needed for embers to transmit out of the unit. The three observed spot fires fall within areas with high RSP.

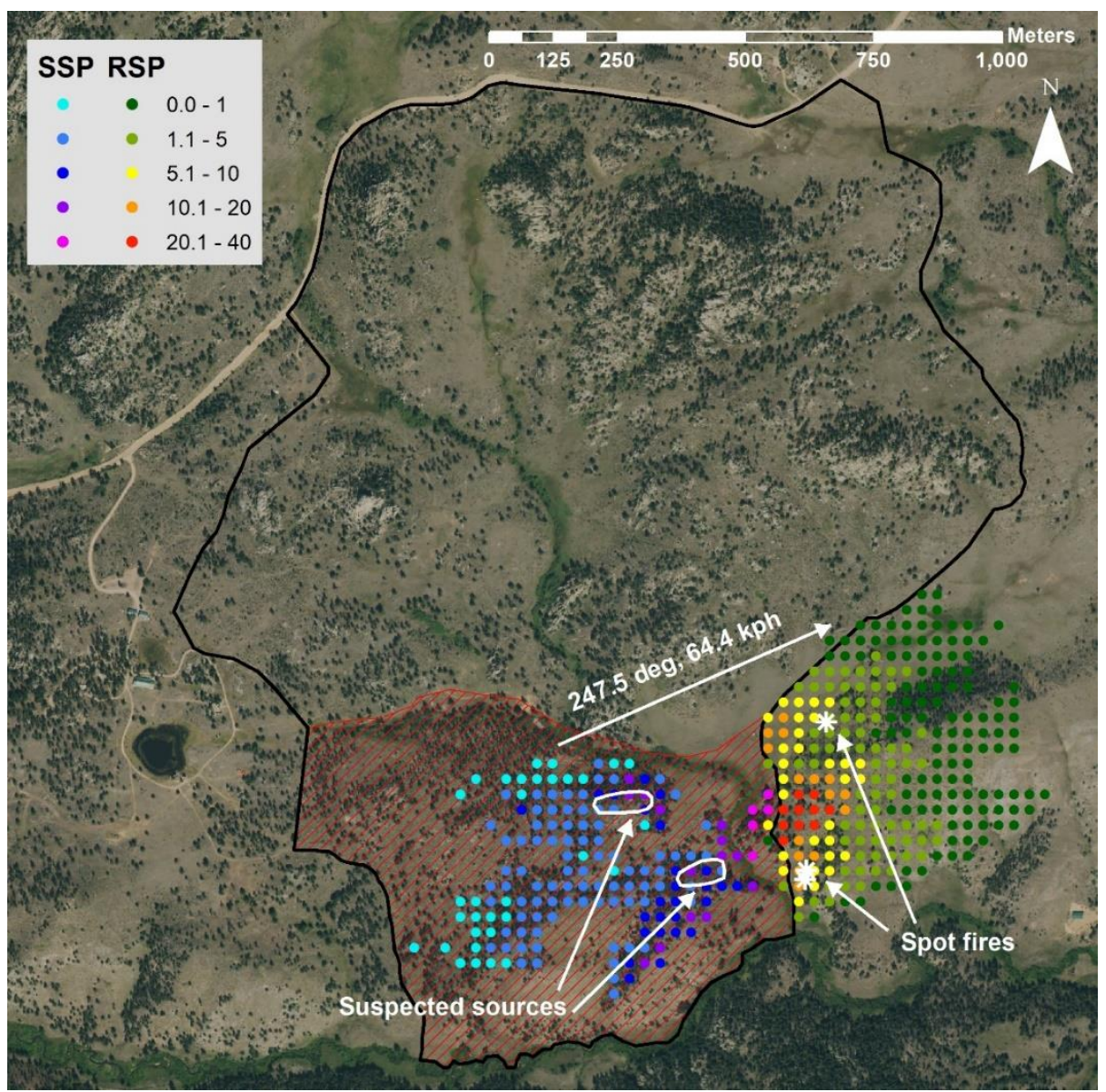


Figure 5. Source spotting potential (SSP) and receiving spotting potential (RSP) for peak gust speed and direction associated with the Elk Fire. Suspected ember source locations and observed spot fire locations from the after-action review [33]. The actively burning unit is hatched red and the planned containment boundary is in black.

SSP, RSP, and TSP for the range of planned prescribed fire conditions (Table (1)) are shown in Figure (6). At the low end of planned burn conditions, TSP is low (total = 7.8) and both SSP and RSP are near the containment lines where detection and likelihood of containment are high. TSP increases considerably for the preferred burn conditions (total $=151$ ). The ember sources are forested hillslopes that are higher than much of the terrain outside the burn unit. SSP and TSP extend approximately $400 \mathrm{~m}$ into and outside the unit, respectively. At the high end of the planned burn conditions, the source areas expand slightly and the total TSP increases to 643 , which is approximately $80 x$ higher than the low scenario and $4 x$ higher than preferred scenario. For the high scenario, ember source and receiving areas extend approximately $600 \mathrm{~m}$ into and outside the unit, respectively.
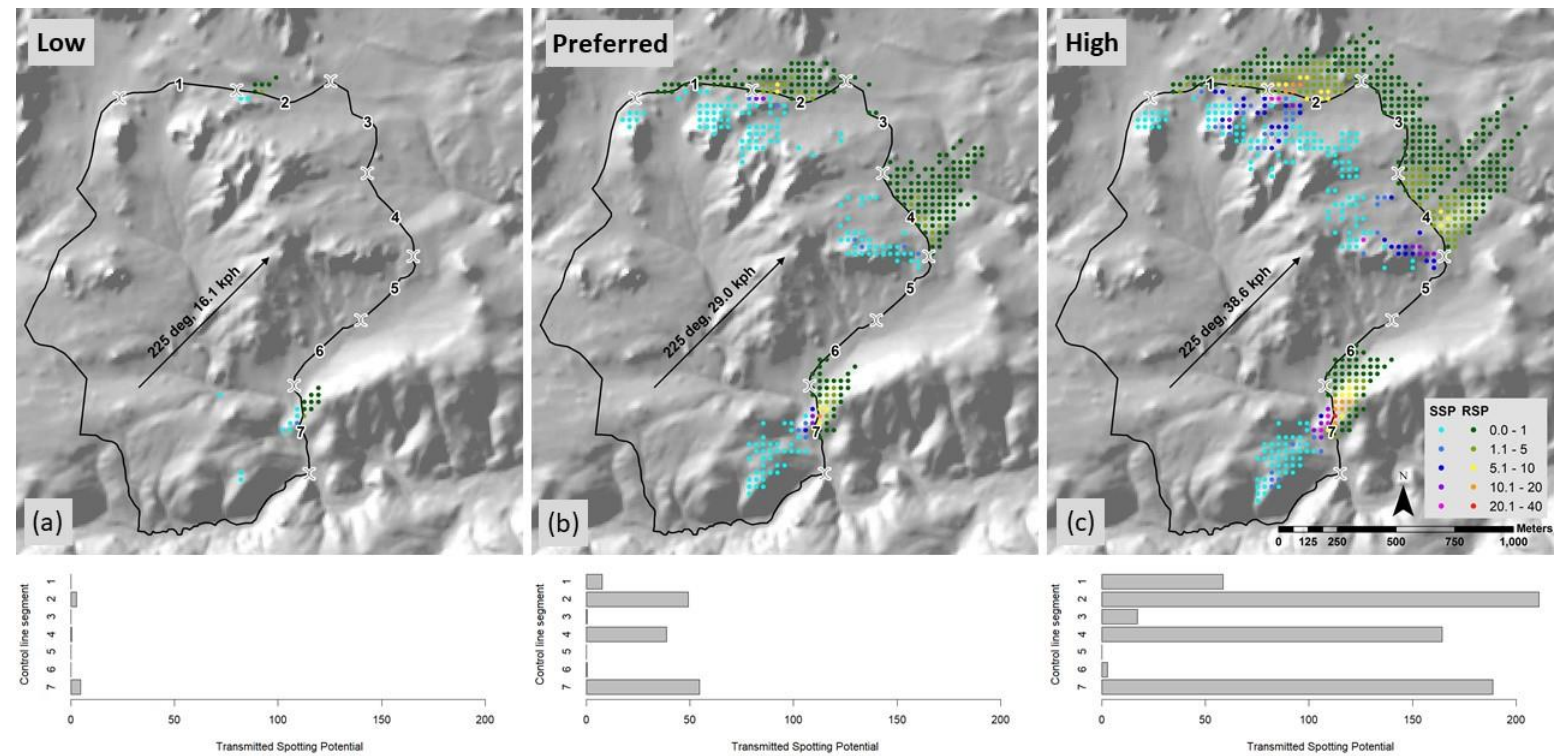

Figure 6. Source spotting potential (SSP) and receiving spotting potential (RSP) for the (a) low, (b) preferred, and (c) high fire weather conditions from the burn plan [33]. Transmitted spotting potential (TSP) is plotted for seven control line segments on the lee side of the planned burn extent.

\section{Discussion}

SP combines models of ember production, transport, and receiving fuelbed ignition in a spatial framework to quantify spot fire transmission potential for source, receiving, and transmitting units of the landscape. The focus on spot fire transmission makes SP more operationally relevant than maximum spotting distance alone and it is a more direct, consistent, and computationally efficient means to evaluate transmission potential than fire spread models that treat spotting as a stochastic process. Furthermore, SP retains spatial information on ember sources and sinks to inform spotting related suppression tasks.

Our test cases show that SP can capture the general patterns of spotting for wind-driven fires. Future research will test the framework in a wider range of conditions. Some spotting on the Decker Fire exceeded the modeled spotting distances, and a considerable proportion of spots were in areas with lower RSP. This could be due to either mis-characterization of the fire environment (wind speed and direction) or behavior (type and intensity), lack of accounting of ember production from the spot fires themselves, imperfect fit of the transport distance probability function, or the limitations of the Albini [6] model. Models to simulate long-range spotting from active crown or plume dominated fires $[20,21,23,34]$ will better predict transport distances under these conditions. For now, SP should 
be used cautiously on fires that exceed the intended scope of the Albini [6] model. We also observed spotting on the Decker Fire that did not align with the single modeled wind direction, likely due to unmodeled wind variability. A strategy to deal with uncertainty in wind direction could be to calculate SP for several wind scenarios and to combine the results with simple or weighted averaging. Poor directional alignment could also result from unaccounted for lateral transport [23].

There is also a need to evaluate and improve the EP and IP components. Estimating EP based on canopy mass engaged in combustion is more consistent than the stochastic production of embers in fire spread models [16], but our assumed scaling relationship is unvalidated. We also did not account for several factors that may influence ember generation including inter-species differences in bark, branch, foliage, cone, or wood characteristics and the presence of standing dead or downed trees from windthrow or insect mortality [35-38]. The focus on canopy fuels is clearly a limitation for SP assessment in non-forest environments. Our vision is that different measures of fire behavior and fuel characteristics could be substituted into the framework to predict spotting in other fuel types. Progressing towards absolute estimates of EP would improve the utility of SP. The IP component relies on a commonly used but incomplete model [25] that is missing important details on the type, amount, arrangement, and continuity of the receiving fuels.

Estimates of containment probability are critical for suppression planning, yet few models evaluate the effectiveness of control lines exposed to spotting. Experimentation has shown that spotting increases breach probability [2], but it would be difficult and costly to develop similar models for different environments. Ensemble fire spread models (e.g., [8]) can be used to estimate the probability of spot fire transmission across barriers to surface fire spread, but this method is computationally intensive and subject to analyst choice of spot fire probability. SP offers a conditional estimate of spot fire transmission based on the same processes of ember production, transport, and receiving fuelbed ignition with lower computational demands. A limitation of SP is that empirical research is required to establish the relationship between TSP and spot fire probability. A potential advantage of empirically calibrating SP over predicting spot fire probability with primary variables (fuel type, wind speed, fire intensity, etc.) is that SP accounts for the driving factors mechanistically, so the model may be applicable to a wider range of environments.

The ability to quantify and map SP should help managers prioritize the allocation of suppression resources. Measures of TSP could be used in the planning phase to prioritize containment where SP is low and, in the control phase, to shift resources to divisions with high risk of containment breaches. Maps of SSP and RSP magnitude, continuity, and depth could help managers think prescriptively about mitigating actions. For example, SSP could inform the depth of burnout needed to mitigate spotting in advance of forecasted weather changes, and RSP could inform the type (e.g., hand, engine, or aerial), amount, and location of resources assigned to spot fire patrol and containment. SP has potential for use in quantitative models of suppression resource needs similar to those used for fireline construction (e.g., [11]) because there are clear pathways to relate some suppression actions to SP; for example, fuels reduction on the fire side of the line will lower EP by avoiding crown fire activity, and retardant application on the green side of the line will lower IP. SP should also be useful for pre-fire fuel treatment planning. We avoided discussion of pre-fire applications here because they require complementary information on the probability of exposure to various fire conditions.

\section{Conclusions}

The SP framework provides an operationally relevant measure of spot fire transmission potential conditional on specified fire extent and weather. Our application of SP to two test cases demonstrates that it can capture the general trends in spotting activity for wind driven fires. In its current form, SP is best suited for relative evaluations, but it can still provide useful information for operations. Control line TSP measures have potential to inform incident-level decisions of fireline selection and resource allocation. Fine-scale mapping of SSP and RSP has promise for informing tactical decisions such as the depth of fuel removal or retardant application adjacent to control lines. Research priorities are evaluating SP performance in other environments, refining the component models, and quantifying the effectiveness of resources on spotting related suppression tasks. 
Author Contributions: Conceptualization, B.G., M.P. and Y.W.; methodology, B.G.; software, B.G.; validation, B.G.; formal analysis, B.G.; investigation, B.G. and M.T.; resources, Y.W.; data curation, B.G.; writing-original draft preparation, B.G.; writing - review and editing, B.G., Y.W. and M.T.; visualization, B.G.; supervision, Y.W.; project administration, Y.W.; funding acquisition, M.T. All authors have read and agreed to the published version of the manuscript.

Funding: This research was funded by joint venture agreement 14-JV-11221636-029 between the USDA Forest Service Rocky Mountain Research Station and Colorado State University.

Acknowledgments: The authors thank Michael Caggiano and Christopher O'Connor for feedback on the model.

Conflicts of Interest: The authors declare no conflict of interest.

\section{References}

1. Green, L.R. Fuelbreaks and other fuel modification for wildland fire control; USDA Forest Service: Washington D.C., USA, 1977; Agriculture Handbook No. 499.

2. Wilson, A.A.G. Width of firebreak that is necessary to stop grass fires: some field experiments. Can. J. For. Res. 1988, 18, 682-687. doi:10.1139/x88-10

3. Agee, J.K.; Bahro, B.; Finney, M.A.; Omi, P.N.; Sapsis, D.B.; Skinner, C.N.; van Wagtendonk, J.W.; Weatherspoon, C.P. The use of shaded fuelbreaks in landscape fire management. For. Ecol. Manage. 2000, 127, 55-66. doi:10.1016/S0378-1127(99)00116-4

4. Koo, E.; Pagni, P.J.; Weise, D.R.; Woycheese, J.P. Firebrands and spotting ignition in large-scale fires. Int. J. Wildland Fire 2010, 19, 818-843. doi:10.1071/WF07119

5. Storey, M.A.; Price, O.F.; Sharples, J.J.; Bradstock, R.A. Drivers of long-distance spotting during wildfires in south-eastern Australia. Int. J. Wildland Fire 2020, 29, 459-472. doi:10.1071/WF19124

6. Albini, F.A. Spot fire distance from burning trees - a predictive model; USDA Forest Service, Intermountain Forest and Range Experiment Station: Ogden, UT, USA, 1979; General Technical Report INT-29.

7. Finney, M.A. FARSITE: fire area simulator - model development and evaluation; USDA Forest Service, Rocky Mountain Research Station: Fort Collins, CO, USA, 2004; Research Paper RMRS-RP-4.

8. Finney, M.A.; Grenfell, I.C.; McHugh, C.W.; Seli, R.C.; Trethewey, D.; Stratton, R.D.; Brittain, S. A method for ensemble wildland fire simulation. Environ. Model. Assess. 2011, 16, 153-167. doi:10.1007/s10666-0109241-3

9. Quintilio, D., Anderson, A.W. Simulation study of initial attack fire operations in the Whitecourt Forest, Alberta; Environment Canada, Canadian Forest Service, Northern Forest Research Centre: Edmonton, Alberta, Canada, 1976; Information Report NOR-X-166.

10. Mees, R.; Strauss, D.; Chase, R. Modeling wildland fire containment with uncertain flame length and fireline width. Int. J. Wildland Fire 1993, 3, 179-185. doi:10.1071/WF9930179

11. Mees, R.; Strauss, D. Allocating resources to large wildland fires: a model with stochastic production rates. For. Sci. 1992, 38, 842-853.

12. O'Connor, C.D.; Calkin, D.E.; Thompson, M.P. An empirical machine learning method for predicting potential fire control locations for pre-fire planning and operational fire management. Int. J. Wildland Fire 2017, 26, 587-597. doi:10.1071/WF16135

13. Rodrigues, M.; Alcasena, F.; Gelabert, P.; Vega-García, C. Geospatial modeling of containment probability for escaped wildfires in a Mediterranean Region. Risk Anal. 2020, 40, 1762-1779. doi:10.1111/risa.13524

14. Haas, J.R.; Calkin, D.E.; Thompson, M.P. Wildfire risk transmission in the Colorado Front Range, USA. Risk Anal. 2015, 35, 226-240. doi:10.1111/risa.12270

15. Ager, A.A.; Palaiologou, P.; Evers, C.R.; Day, M.A.; Barros, A.M.G. Assessing transboundary wildfire exposure in the southwestern United States. Risk Anal. 2018, 38, 2105-2127. doi:10.1111/risa.12999

16. Finney, M.A.; Brittain, S.; Seli, R.C.; McHugh, C.W.; Gangi, L. FlamMap: fire mapping and analysis system, version 6.0; USDA Forest Service, Rocky Mountain Research Station: Missoula, MT, USA, 2019.

17. LANDFIRE. Fuel, Topography, and Existing Vegetation Type Layers, Version 2.0.; USDOI Geological Survey: Washington, DC, USA, 2019. Available online: http://landfire.cr.usgs.gov/viewer/(accessed on 23 August 2019).

18. Scott, J.H.; Reinhardt, E.D. Assessing crown fire potential by linking models of surface and crown fire behavior; USDA Forest Service, Rocky Mountain Research Station: Fort Collins, CO, USA, 2001; General Technical Research Paper RMRS-RP-29. 
19. Cruz, M.G.; Alexander, M.E.; Wakimoto, R.H. Assessing canopy fuel stratum characteristics in crown fire prone fuel types of western North America. Int. J. Wildland Fire 2003, 12, 39-50. doi:10.1071/WF02024

20. Sardoy, N.; Consalvi, J.L.; Kaiss, A.; Fernandez-Pello, A.C.; Porterie, B. Numerical study of ground-level distribution of firebrands generated by line fires. Combust. Flame 2008, 154, 478-488. doi:10.1016/j.combustflame.2008.05.006

21. Wang, H-H. Analysis on downwind distribution of firebrands sourced from a wildland fire. Fire Technol. 2011, 47, 321-340. doi:10.1007/s10694-009-0134-4

22. Martin, J.; Hillen, T. The spotting distribution of wildfires. Appl. Sci. 2016, 6, 177. doi:10.3390/app6060177

23. Thurston, W.; Kepert, J.D.; Tory, K.J.; Fawcett, R.J.B. The contribution of turbulent plume dynamics to longrange spotting. Int. J. Wildland Fire 2017, 26, 317-330. doi:10.1071/WF16142

24. Schroeder, M.J. (1969) Ignition probability; USDA Forest Service, Rocky Mountain Forest and Range Experiment Station: Fort Collins, CO, USA, 1969; Office Report 2106-1.

25. National Wildfire Coordinating Group (NWCG). Probability of ignition. Available online: https://www.nwcg.gov/publications/pms437/fuel-moisture/probability-of-ignition (accessed on 25 October 2020).

26. R Core Team. R: a language and environment for statistical computing, version 3.5.3; R Foundation for Statistical Computing: Vienna, Austria, 2019. Available online: http://www.R-project.org/(accessed on 27 August 2019).

27. Hijmans, R.J. raster: Geographic Data Analysis and Modeling, R package version 2.8-19; 2019. Available online: https://CRAN.R-project.org/package=raster (accessed on 27 August 2019).

28. Bivand, R.; Keitt, T.; Rowlingson, B. rgdal: Bindings for the 'Geospatial' Data Abstraction Library, R package version 1.4-3; 2019. Available online: https:/CRAN.R-project.org/package=rgdal (accessed on 27 August 2019).

29. Bivand, R.; Rundel, C. rgeos: Interface to Geometry Engine - Open Source ('GEOS'), R package version 0.4-2; 2018. Available online: https://CRAN.R-project.org/package=rgeos (accessed on 27 August 2019).

30. Wickham, H. The split-apply-combine strategy for data analysis. J. Stat. Software 2011, 40, 1-29. doi:10.18637/jss.v040.i01

31. National Interagency Fire Center (NIFC). Fire perimeter records; National Interagency Fire Center: Boise, ID, USA, 2019. Available online: www.nifc.gov (accessed on 1 September 2020).

32. National Wildfire Coordinating Group (NWCG). Incident Status Summary Report for the Decker Fire; National Wildfire Coordinating Group: Washington, DC, USA, 2019. Available online: https://fam.nwcg.gov/famweb/(accessed on 1 September 2020).

33. Colorado Division of Fire Prevention and Control (CDFPC). Elkhorn Creek Unit \#4 prescribed fire review; Colorado Division of Fire Prevention and Control: Lakewood, CO, USA, 2020; Available online: https://www.colorado.gov/pacific/dfpc/elkhorn-creek-unit-4-prescribed-fire-review (accessed on 31 March 2020).

34. Albini, F.A.; Alexander, M.E.; Cruz, M.G. A mathematical model for predicting the maximum poptential spotting distance from a crown fire. Int. J. Wildland Fire 2012, 21, 609-627. doi:10.1071/WF11020

35. Ellis, P.F.M. Fuelbed ignition potential and bark morphology explain the notoriety of the eucalypt messmate 'stringybark' for intense spotting. Int. J. Wildland Fire 2011, 20, 897-907. doi:10.1071/WF10052

36. Page, W.G.; Alexander, M.E.; Jenkins, M.J. Wildfire's resistance to control in mountain pine beetle-attacked lodgepole pine forests. The Forestry Chronicle 2013, 89, 783-794. doi:10.5558/tfc2013-141

37. Moriarty, K.; Cheng, A.S.; Homan, C.M.; Cottrell, S.P.; Alexander, M.E. Firefighter observations of "surprising" fire behavior in mountain pine beetle-attacked lodgepole pine forests. Fire 2019, 2, 34. doi:10.3390/fire2020034

38. Bahrani, B.; Zhuo, A. Firebrands generated from selected vegetative fuels. Fire Protection Engineering 2020, Q2, 34-40.

Publisher's Note: MDPI stays neutral with regard to jurisdictional claims in published maps and institutional affiliations.

(C) 2020 by the authors. Submitted for possible open access publication under the terms and conditions of the Creative Commons Attribution (CC BY) license (http://creativecommons.org/licenses/by/4.0/). 
